\title{
Children participating as researchers in primary schools: what's in it for the teachers?
}

\section{Introduction}

This paper draws on findings from a project, 'Pupils as research partners in primary' (PARPP), which is a schools and university-based partnership that co-creates pupil-led research opportunities and activities in primary schools. Regionally, PARPP aims to encourage the growth of a research community network for primary schools (for pupils aged 4- 11) who are already working in partnership with the university through its initial teacher training and postgraduate teaching programmes. The university in this study is located in the West Midlands in England, UK, which has a growing reputation for innovation and excellence in child-led research. It regards PARPP as an exciting way to enhance and promote their existing work in this area in line with the recent BERA/RSA report (2014) which states in its Introduction that:

...schools and colleges [should] become research-rich environments in which to work [and] that teacher researchers and the wider research community work in partnership, rather than in separate and sometimes competing universes. (p.5)

In universities, research with young children is already well-established, for example, the Open University's Children's Research Centre (http://childrens-research-centre.open.ac.uk) was created to support and promote research by children in the UK. Other Childhood Studies and Early Years departments have pioneered the use of innovative research practices, often developed out of work in and around children's agency and rights. This includes Clark and Moss's ground-breaking work on the Mosaic approach (2001); explorations into the ethical implications of new research methodologies for working with children (Greene and Hogan, 2005); the work of academics drawing on Deluzean and feminist research traditions for their work with and on children (Jones, Osgood, Holmes, and MacLure, 2014). These innovations are in addition to the challenges thrown down to traditional conceptions of childhood by academics (Osgood, 2016; House, 2011) and wider campaigns such as the 'Open EYE Early Childhood' campaign, which was formed in the autumn of 2007, and subsequently merged with the Early Childhood Action group in early 2013. PARPP has drawn on this important academic and campaigning field in early years education as it takes as its starting point children's agency, repositioning them as active researchers into their lives, experiences and opinions as children.

Disappointingly, there is nothing directly in the Carter Review (a report commissioned by the UK Government to review of the quality and effectiveness of initial teacher training (ITT) courses), or one of its core responses to the Carter Review, the Framework of Core Content for Initial Teacher Training, which were both published in 2016, that refers to the role or potential importance of pupil-led research in primary education. However, more encouragingly, the British Education Research Association (BERA) / Royal Society for the encouragement of Arts, Manufactures and Commerce ( RSA) Report on Research and the 
Teaching Profession (BERA, 2014) argues that schools should be 'research-rich environments' and for teachers to be 'research literate' across a variety of paradigms and methodological approaches (foreword). The PARPP project's child-led approach to research in schools, draws on the epistemological principals of emancipatory and participatory research, which it argues, lend themselves philosophically and ontologically to pupil-led research projects. These principles reflect the BERA/RSA Report's advocacy of a broad and inclusive definition to the term "research" in schools.

In this paper we report on the experiences of those teachers who responded to an offer for their pupils to take part in the PARPP project. Invitations were sent out, via a mail shot, in 2016 to all link-schools associated with the University's Initial Teacher Training programme for Primary. Having agreed to allow pupils in their school to take part the teachers took a back-seat observers role with regard to the research projects, which were co-constructed between the PARPP workers and the pupils (with the exception on Case Study 4, see below for details).

Despite their minimal involvement we have chosen in this paper to focus on the teachers' perceptions of PARPP as there is evidence to suggest that however experienced and confident they are, teachers are often unsure and/or unwilling to engage in pupil-led research, especially with young children (Kellett, 2010). This reluctance may be due in part to the principles underpinning participatory/emancipatory research, which are the models used in PARPP which necessarily involve primary teachers working more interactively with their pupils, trying out new approaches and taking risks. Schools, after all, are carefully delineated spaces where teachers and pupils function along carefully organised lines that are governed and legitimated through constant repetition and the power invested in those adults who are in charge. Such a relatively controlled environment can inhibit participatory research activities, as pupil-led research, its processes and outcomes, can be unpredictable and even unwelcome (Leat, Reid and Lofthouse, 2014). Teachers are consequently often unwilling to accept, or are unsure about the implications of allowing the rights around participation and consultation required by pupil-led research (Lowe, 2012). It is not surprising, therefore, that even when school-based research involving pupils working with teachers is considered, or even carried out in primary schools, it often struggles because it challenges discourses of early childhood that construct pupils as too immature to carry out research responsibly and without direct supervision by their teachers. This paper, drawing on the experiences of teachers observing the PARPP projects in their school, specifically asks the question, 'can observing and/or experiencing pupil-led research help teachers more readily appreciate and support pupils as researchers in their own right'.

\section{Teachers as Researchers}

Despite the recent government interest in teacher researchers evidenced by the BERA/SIG report in 2014, the experience of primary teachers as researchers is relatively underresearched. For this reason, PARPP, in addition to thinking about how child-led research would affect the primary pupils taking part, became very interested in how observing the project would affect the teachers involved. In particular, the project team hoped that the teachers reaction to PARPP would help open up more emancipatory, participatory ways for 
them to think, not just about how they might research with pupils, but about their professional practice in the classroom more generally. Although participating in the PARPP project reflected many of the teachers' genuine desire to engage creatively and agentically with the pupils in their school, our findings suggested that our participatory research approach certainly highlighted disjunctions between everyday primary teacher practices and perceptions of role, which did not normally include facilitating child-led research activities and the challenges and the perceived risks and demands it was often felt to involve.

For example, in 1981, Stenhouse observed that the main constraint on teachers' active participation in research was time, or the lack of it. Thirty-five years later Leat et al (2014) also identify teachers' concerns about the effect of carrying out research on their relationships with fellow professionals and a lack of confidence in their personal ability to carry out research (with or without children as co-researchers). In addition, relationships with head teachers, governing bodies and Local Authorities were identified as barriers to conducting and engaging with research. Specifically, teachers worried if they would be trusted to do research by senior colleagues, and if they were, often voiced doubts that it would actually be taken account of in their workplace.

Leat et al (2014) concluded, however, that teachers generally feel positive about engaging in research as long as it focussed on professional development, managing change, improved performance and/or pupil outcomes. Similarly, Beycioglu, Ozer and Uguralu (2010) reported that $68 \%$ of teachers in their study had considered conducting research since qualifying, and their reason for doing so was also largely for professional development purposes. One cannot avoid the idea, in the light of these findings, that the perceived utility of research for teachers, child-led or otherwise, reflects the current focus on performativity that inform teachers', professional identities, so that any activities undertaken by a teacher are expected to '... serve as measures of productivity or output' (Ball, 2003, p.216).

However, one can argue that the use of pupil-led research in primary school is potentially much more than just a vehicle for teachers' professional and personal development. Leat et al (2014) identified a number of socio-emotional benefits to teachers engaging with research which included improved self-esteem, self-confidence, feelings of pride and greater connectivity with peers and colleagues. Newman and Mowbray (2012) looked at research conducted by academics and teachers working together and observed that a significant factor in the success of these collaborative research projects was the emergence of a community of practice around research between the two groups. In their study, mentoring roles were often undertaken by academics in the partnerships which, it was reported, empowered the teachers to feel that they were researchers which in turn they felt, helped enrich their professional lives. Conversely, after engaging in research, Leat et al's (2014) participants found that some of the teacher-researchers in their study subsequently expressed a sense of dissatisfaction with their profession, to the extent that one or two participants actually left teaching. However, the authors acknowledge that the research may have brought to the surface doubts, feelings or questions about teaching that were already there.

Suspicion and a lack of confidence around child-led research is often inculcated at undergraduate level. Many teacher trainees and undergraduates on Early Years /Childhood 
Studies/Education Studies undertaking independent research as a part of their degree are often explicitly warned off conducting research involving children in any capacity for a variety of reasons. Logistically there is the issue of getting access to children for some student researchers. There is also the important issue of ethics which needs to be assured and monitored by the HEI concerned.

In primary schools specifically, there is evidence to suggest that young pupils, like their teachers, often unconsciously accept that the principles underpinning children's equal participation in research about themselves, their experiences and environment, and the representation on their own terms that it affords about their experiences, do not apply, because they are children (Lowe 2012, p.276). Moreover, children may also be deliberately denied participation in research, ostensibly because they are deemed, often by the adults responsible for them, to be not 'ready' or 'up to it'. In this way children's lack of access to research, is often rationalised through an adult lack of confidence in their capabilities rather than their actual ability or inclination to get engaged in research activities (Heath et al, 2007, Krappmann, 2010). Opportunities for participatory research by primary pupils in schools, and other settings, is, perhaps for these reasons, rarely carried out even though there is plenty of evidence to suggest that it could effectively promote pupils' 'voice', which is clearly a part of government policy in England (DfE, 2014).

Against this backdrop in order to facilitate the kind of engagement in child-led research that the DfE are keen to promote Dockett, Einarsdottir and Perry (2009) argue that there is a need to reflect on the processes and outcomes of the range of approaches aimed at promoting children's engagement in research, and listening to children's voices. They suggest that contextual and relational variables should guide research interactions, whilst insisting that no 'one best solution' is applicable to all contexts. This reflects the principles of participatory research methodologies which encourage the use of a mixture of materials and techniques which can enhance children's communication, for example by giving them time to think about what they would like to communicate, so they do not feel pressured to give a rapid answer (Punch, 2002).

PARPP's, child-led approach to research with primary pupils sought to reposition the project workers, albeit temporarily, as equal co-researchers who worked with, rather than on behalf of the pupils. Like other advocates of child-led research, the PARPP team maintained that children's' perspectives and understanding are especially useful when researching their immediate lived experience of 'being a child' in particular settings, such as school.

Children's perspectives on, and ability to understand, social situations may be different from adults' however, they can be just as valuable and perceptive. Initiatives like PARPP, therefore present opportunities for pupils in their school settings to be active participants in the construction of meaning within the school environment (Taylor and MacKay, 2007).

Most researchers and commentators identify Article 12 (UNCRC 1989), as the starting point, albeit a problematic and often ambiguous one, for the concept of the child's 'Right to Participation' (Lundy, 2007, Krappmann, 2010; Ruck and Horn, 2008). Although Article 12 does not actually use the word 'participation', it does state that; 
State parties shall assure to the child who is capable of forming his or her own views the right to express those views freely in all matters affecting the child, the views of the child being given due weight in accordance with the age and maturity of the child...for this purpose, the child shall in particular, be provided with the opportunity to be heard in any judicial and administrative procedures affecting the child (Article 12).

PARPP, in line with Article 12 precepts, was explicitly designed to encourage young children, through participation in research activities, to 'express their views freely' and as importantly to be 'heard' by their teachers. In this vein Rinaldi (2006), discusses the need for a 'pedagogy of listening' that allows space for children's views to be heard and which has the potential to generate understanding and awareness in educational settings. This reflects PARPP's belief that child-led research in primary schools can enhance positively pupils's self-development and political agency as illustrated in other research involving very young children (Bucknall, 2012; Cremin and Slatter, 2004; Einarsdottir, Dockett and Perry, 2009). In many schools pupils have been successfully elected onto school project steering groups, helped write research project briefs as well as being actively encouraged to take part in data collection, often through the use of digital technologies such as video and Facebook (Kerawalla, 2014; Kerawalla and Webb, 2014) or through innovative methodologies such as the Mosaic Approach (Clark and Moss, 2001) which are designed to enable the very youngest children's voices to be heard in research.

\section{Methodology}

Child-led research requires the adoption of broadly a participatory research paradigm which requires more than simple collaboration between researchers and participants, be they children or adults. Adopting a participatory approach also demands a non-hierarchical pedagogy which seeks to enable children to become researchers in their own right. Equality and mutuality are therefore at the heart of child-led research decision making processes and implementation, from research design through to analysis of data and dissemination of findings (Staley, 2009 in Lewis, MacNaughton and Nicholls 2014). Reflecting this approach, the pupils in the various PARPP projects under consideration here, were actively involved in exploring how they should engage with the research processes through discussion and questioning. For example, in PARPP researchers adopted a social constructivist pedagogy to facilitate pupils' understanding of what the project involved. In the first session they were asked to discuss the following questions: What did they think researchers did? Had they carried out research before? (Pupils usually referred to research carried out for 'projects' in their discussion of this question). What did they research into their school activities/setting research might achieve? In this way the pupils were encouraged to reflect and actively engaged in the processes they were about become involved in. This method of questioning and discussion continued throughout the project lifespan to cover the design of the project, 
the analysis of data and so on. The pupils' responses were captured through field-notes by PARPP researchers and will be used to inform another paper reporting on the project.

\section{Pupil Sample}

In each setting it was adults, variously teachers, Heads and teaching assistants, who liaising with PARPP, selected the pupil groups to be involved. In some instances this was a preexisting group like the School Council (note: a school council is group of pupils who are elected by their peers to represent the views of all pupils and address issues raised by pupils with the school), a whole year group, or selected classes). In all but one project, the adults' only involvement in the project was to facilitate the research by, for example, getting equipment, safeguarding, mediating with project workers and offering support when it was asked for. In those cases where PARPP worked with School Councils the member of staff who normally facilitated those sessions sat in and observed. In others it was the teacher or teaching assistant who had initially made contact with the PARPP project workers who stayed with them whilst the PARPP project workers engaged directly with the pupils. The only exception to this non-participation was Case Study 3 where two teachers took a preexisting 'New school garden project' research forward and worked with the pupils by themselves. Their sole involvement in this case was down to teacher choice which the PARPP researcher encouraged. However, PARPP worked closely with the teachers to coconstruct ways of involving their very young pupils (aged 4-7) in the design of the garden.

Five completed PARPP projects were carried out in 2016 in four different primary settings using various forms of child-led research. The schools were very different from one another in terms of size and geographical location, which was due more to accident than design, as these were the schools that responded to a flyer about the project sent out to all the university's school partners, which number several hundred. (Other PARPP projects were embarked upon during this period but for a variety of reasons did not reach completion and have not therefore been included in this paper).

In each setting the PARPP team made it clear to the pupils in the initial preparatory session that the university-based PARPP researcher had a role outside the school although they clearly shared some attributes of a teacher (not least they were adults). Thereafter the project team met only with the pupils who had been selected to take part in the project.

The practical application of child-led research in each setting used in the PARPP project had the following informing principles that sought to:

- $\quad$ respect pupils' views

- $\quad$ advocate for the pupil's active participation in research and learning activities

- $\quad$ promote pupils' learning and reflection about their lives and environments facilitates pupils' understanding of development issues for themselves and their wider communities

- develop pupils' decision-making and problem solving abilities in order to take action on identified priorities

- $\quad$ develop pupil's ability to communicate, empathise and cope with difficult circumstances 
- $\quad$ recognises pupils' potential as change agents.

(Adapted from the Child to Child webpage: www.childtochild.org.uk)

Case studies

Case Study 1 Exhibition Evaluation/Marking project (medium-sized urban Primary FSM: 10.3 in Jan 2016)

Title: Pupils as Evaluators project

Methods: School Council developed and carried out a questionnaire on whole school exhibition

Output: 2 joint conference presentations and joint published paper with participating teaching assistant

\section{Case Study 2 (medium-sized urban Primary FSM: 10.3 in Jan 2016)}

Title: Evaluation of whole school marking scheme

- Methods: Online Survey on Marking Scheme developed and carried out across the whole school by pupils working group drawn from the School Council.

- Output: feedback to senior management representatives with responsibility for the school marking policy

\section{Case Study 3 (small urban infant school FSM: 13.3 in Jan 2016)}

- Title: New School Garden project

- Methods: Garden space project developed by teachers who worked directly with pupils from Yr. 2: ( two classes) involved in the first instance to develop project then involved the whole school in commenting on Yr. 2 plans

Output: School exhibition on parents evening to help raise fund for the work to be carried out

Case Study 3 (medium rural primary FSM: 4.7 in Jan 2016)

- Title : Computers in school

- Methods: Online survey developed with School Council members about IT use in school and at home. Piloted with Yr. 4

- Output: Plans to revise in the light of the pilot and roll out across the school

Case Study 4 (very large urban primary FSM: 30.5 in Jan 2016)

- Title: Transitions

- Methods: 4 x Yr. 3 groups involved in drawing activity about transition to year $2 / 1 \mathrm{x}$ Yr. 2 group focus group reported on expectations around transition ( through drawing)

- Output: PowerPoint developed out of pupil pictures and transcripts as a resource for staff, pupils and parents

The project design followed Yin's 'exploratory case study' model (2003) which reflected our key research question for this paper, namely: 'can observing and/or experiencing pupil-led research help teachers more readily appreciate and support pupils as researchers in their own right'. After completion of each case study the teachers involved were interviewed by PARPP researchers using a semi-structured framework which allowed enough flexibility to account for differences in each setting whilst simultaneous ensuring 
some consistency around key ideas that we wished to pursue with the teachers such as 'Did you know much about participatory research with children before your involvement in the PARPP project?' and 'Could pupil-led research have wider benefits in schools'? These interview transcripts were then analysed using an open analytic approach which sought to capture the experiential nature of the data and focussing more on establishing themes rather than the establishment of any firm hypothesis (Cohen, Manion, and Morrison, 2007). This open coding resulted in the identification of a number of common area for discussion (and possibly further research) which are discussed below.

\section{Ethical concerns}

PARPP was an internally-funded project which satisfied the University's Faculty's ethical board before beginning the research. In each setting approval to work with the pupils was given by the school and the PARPP workers themselves had no contact with parents. However, over and above these formal procedures ethical concerns about children getting involved in research included consideration of important issues such as ensuring informed consent and the right to withdraw as well as the potential misrepresentation of children's views and experiences by adult researchers. In addition, the PARPP workers were aware that adults in a setting with responsibility for children, such as practitioners, teachers or parents, often position themselves as gatekeepers with regard to requests to conduct research from students. Justifiably, they too are keen to ensure protection for the children in their care from any potential harm occasioned by researchers and their interventions and/or data collection methods. Heath, Charles, Crow and Wiles (2007), for example, reflect on the conflict that can arise between the often constricting consent practices of practitioners working with children and young people and those researchers who seek to involve them more agentically in research, specifically when it is about their lives and experiences.

Clearly such tensions needed to be acknowledged and addressed in PARPP, however, there has been only a limited debate about the ethical complexities of researching with children, despite a growth in awareness and understanding of situational ethics. For example, one can argue that child-led research is intrinsically ethical as it put the children at the centre of the research process. Moreover, Gallacher and Gallagher (2008) offer concerns about participatory approaches when researching with children, suggesting that the very rigour of the research tools, adult-chosen, adult-designed can reinforce the position of power and control in the hands of the adult researchers and, as such, these approaches often fail to be fully participatory. Clearly, PARPP (as discussed above) reflects these concerns as it allowed the teachers to chose the research focus for each project. However, once underway every attempt was made to leave the children in control of the methods to be used. Moreover, in the introductory sessions a great deal of time was spent discussing the ethical implications of each project with the pupils through discussion. For example in Case Studies 2 and 3 we discussed what to do if someone did not want to take part in the questionnaire and which questions were appropriate to ask. In case study 4 we talked about why it was important that the contributions were anonymous. In each case we found the pupils to have strong ethical scruples and real sensitivity towards their co-researchers and their participants. 


\section{Findings}

Although most of the teachers interviewed for this paper were not directly involved in the PARPP research activities, their interest had certainly been piqued by it. They were keen, as one teacher put it 'to see how it worked in practice' (PARPP researcher field-notes). Indeed, as the project progressed in each school the teachers did watch with keen interest as the PARPP researcher worked with the pupils. Indeed they often made comments after the sessions (usually whilst clearing up the room with the researcher) about how surprised they were by the pupils' level of engagement, what they actually produced and how they conducted themselves. It was this clear personal effect of the project on the teachers that led the project workers to decide to interview them formally to explore how they felt about the processes of pupil-led research that they had observed during the life of the project in their settings.

\section{Benefits to pupils}

One key aspect of the interviews, unsurprisingly, focused on what they thought the PARPP project had told them about their pupils. Of especial interest was question of whether teachers' reflections on the pupils' experience of the project had challenged their assumptions about the role they had thought primary pupils could play in research prior to taking part in the project. The majority observed that they had not thought that that pupils would be ready to take part so proactively in research as 'they do not listen enough/ or in the right way'. There was also a concern that the project had not explicitly prepared the children to be active pupil-researchers ' will they need to be explicitly taught how to do research? These concerns were possibly compounded in these primary school settings as many of the pupils involved were so young (all the projects involved some children aged 4-11). However, in practice it was acknowledged that participating in the PARPP projects had provided all pupils with opportunities to deploy, with very little overt teaching, valuable research skills such as setting and asking questions and thinking about research ethics (for example, who to ask, when not to ask, what to ask). The pupils' high level of ability and performance in these areas was usually greater than their teachers 'expectations.

[...] people here thought we couldn't get four, five, six and seven year olds to have a voice. Colleagues thought it would be a bit silly but actually they're [the pupils]are just as sensible as if we'd done it so why can't we say to them, 'do what you want'. (Helen)

The PARPP team reviews of each project (and their contemporaneous field-notes) revealed that pupils across all the projects took key decisions and influenced the way the research projects operated; pupils took the projects very seriously and worked hard with little or no supervision from their teachers or the PARPP researcher. Across the different projects various research approaches were decided upon by the pupils; research tools such as questionnaires, mood-board and online surveys were constructed and in the data analysis stage the information gathered was discussed by the pupils. All these activities involved a lot 
of decision-making between the different pupil group members, who, often in mixed age groups, worked together very supportively and collaboratively to get things done.

In the interviews conducted after each project the teachers overwhelmingly reported that they felt that the PARPP project in their school had empowered pupils, who had developed ideas and made decisions about issues that affected them and their fellow pupils across the wider school. Most importantly for the PARPP researchers the teachers reported that they felt that during the project they had had to listen and defer to the pupils more carefully than they normally did.

The [PARPP researcher] came into school and devised a questionnaire with the kids [...] so that they took control of it rather than me just writing it. (Eva)

Moreover, the teachers observed that the pupils had no compunction in challenging the researcher working with them about the wording of questions or interpretation of data. In this way the teachers (who were usually in the position of just observing what was going on during the research) felt that the pupils responded positively to their more autonomous research environment which was far from the typical classrooms environment with its injunctions to 'sit still' and 'listen carefully'.

From what I've seen today it looks like the children are very positive, we've had [the PARPP researcher) coming in to work with them, we've had a visiting professional and that increases the fabric of the children's experiences. (David)

In a previous paper looking at PARPP projects, French and Hobbs (2017) discussed how pupils reacted positively to the 'third space' (Oldenburg, 2000) created by the PARPP project workers.

It helped that I wasn't a teacher, it allowed for a third space and children were freer in the classroom. (PARPP researcher 1)

The teachers agreed that the freedom that such third, or in-between spaces, offered the pupils was significant as it helped break down, or at least minimise, the traditional powerimbalance in schools between adult/teacher and child/pupil that often inhibits child-led research initiatives (Kellett, 2010). They also observed that it encouraged the pupils to engage more easily in a different kind of work, conducted through different kind of relationships, with adults who were not their teachers. As one teacher participant commented:

They [the PARPP researchers] were saying to the kids, right up front, what are you gonna ask, what do you want to know, what do you want people to tell you about, what do you want to find out; we [teachers] don't often do that ...(Eva)

Positioned by PARPP researchers as experts in their chosen research area, the pupilresearchers quickly assumed the authority and autonomy that the project approach afforded them. In the teachers' feedback there was a sense that they now had a heightened awareness and empathy with how the pupils normally experienced their more restrictive school environment. 
It [PARPP] was a really useful thing to do because we sit here as teachers and make a lot of decisions for children because we are adults and we know lots of things but actually for things that they are directly involved in, it got me thinking why can't they have a bit of a voice in that too[...] (Helen)

Having seen what the pupils could do as researchers, the teachers were more inclined to think positively about involving the children more in future research projects in the school and even working differently with them.

I haven't seen them do any proper research before. The teachers have now used the pro forma of what we've done [with PARPP] and when they've looked at other topics now they actually give the kids the time and the know-how of how to go about asking things and making up their own questionnaires. (Eva)

During the projects the teachers reported how much the pupils had worked in partnership with their peers, teachers and other professionals and had enjoyed being treated equally, engaging in dialogue and democratic decision-making.

... I posed that question to children that they led it, [the research] and from that point. I just made suggestions and we were surprised at how much they totally ran with it. The children were better than I thought they could possibly be [...] their opinions and are ideas were valued and I also think it got them to think very carefully about what they say because they know what they are going to say is going to be taken seriously. (Nicola)

\section{Pupil Development and Learning}

The teachers felt that what the pupils learnt by being involved in the PARPP projects reflected traditional school pedagogy, but acknowledged that the skills they learnt cut across different curricula, not least because the pupils were agentically engaged in child-centred discovery learning.

[The PARPP project] was reflective of the national curriculum because there was an emphasis on finding on what do you know, what you want to find out, how you are going to find out about it in things like History and Geography and things like that. And like the master curriculum in Maths, they learned that if they have a problem and they have equipment and they choose what equipment they want to use to solve the problem. (Gail)

Teachers reported that the pupils had developed life- skills through PARPP.

[PARPP] was great for the kids, it gave them huge confidence, going up and speaking to strangers and really nice that they were able to talk about more than just the questions that they'd been given, if somebody gave them an answer and then said, what do you think, they were able to speak so that was really good. (Eva)

Through the PARPP research programmes it was clear that the teachers recognised that their pupils had gained confidence, not least because they had been allowed some control over 
what they were doing and how they could use what they had learned during the process of carrying out their research.

They were able to use the information [that they gathered in the research] in their maths work, it was like it was done for a purpose cos so often research can be done and then just put in a corner, so it was nice that the kids actually did something with it. They felt important; they had a real role to play in it. (Nicola)

In this way the PARPP research approach encouraged teachers to see how capable their pupils could be when left supported to develop their autonomy. This experience caused them to reflect on how they might work more in more pupil-centred ways in their own practice.

We're thinking about the children's experience through this research process, it's been very effective because you've had all the experience of speaking and listening to the children's experiences, how they've had to cooperate and show leadership within the group and reflect. So you've got the children's experiences and the teachers' experiences. Finding out how the children felt [about the PARPP project] has been a kind of informal research for [us] so we can build on what they found and build on in future for next year. (David)

During the time spent across the various PARPP projects the teachers who feedback for this paper evinced an interest in how the skills of the pupils emerged through their involvement in the research activities.

We certainly could see the children being able to manage things very much on their own rather than needing the intervention that we thought we had to make. So I think it has moved us on. (Nicola)

It's changed the way that I view the children... I thought we'd have to scaffold their ideas more, that there'd be more outrageous ideas, and we'd have to have a lot more discussion. But actually they're ideas that we would have had in a staff meeting. So I think actually four year olds, if you ask them to have sensible suggestions, they can do it, it's been really interesting from that perspective. (Helen)

This, emphasis on pre-existing outcomes either curricula or professional, was reflected in our research findings, as one participant rather ruefully noted:

We'd do more [child-led-research] if we'd got a head who was open to change, open to trusting in something new, but I don't think she's got enough time to learn what the kids could get out of it because they're not going to show that they've learnt anything from it, you can't tick a box to say they can spell anything any better or write two adjectives in a sentence or anything so because there's no box to tick, she's not interested... (Eva)

This contrasts, however, to the schools in Case Studies 3 and 4 where the Headteachers actively prioritised the opportunity to participate in the project.

\section{Working in Partnership}


As well as what they got from observing the pupils, the teachers in this study also commented on how they felt, like the respondents in Newman \& Mowbray, (2012) that they had benefited professionally from working with research professionals and sharing knowledge about how to develop and implement child-led research through the PARPP projects.

It's been really useful and having [the project workers] come in and help us and tell us what other schools have done and how we might be able to adapt it to this school because I probably wouldn't have had a clue. I went to the conference last year I got to see another school and how they'd used their research project which was really interesting so that was really good. (Sarah)

From this experience the teachers appeared to have developed new skills and confidence which they felt enhanced their own practice:

It has been very helpful for us to have a more objective view of what we're doing, having someone outside looking at it and evaluating it and suggesting ways that we can go forward, particularly in financial terms and having a broader view. (Nicola)

In some schools the PARPP projects had a direct benefit to the whole of the school rather than just the pupils who were involved in the project or just one particular class. For example, in one project teachers, post-PARPP involvement, professed more confidence about putting an innovative research project together which, they now recognised, could potentially bring in external funding to raise their school's profile and enhance resources. As one respondent noted:

We're going to get children to list the things that we will need and that could be part of the bids. (Nicola)

Teachers also recognised that the PARPP project provided opportunities to engage with various school stakeholders in new ways through the methods developed by pupils working as researchers:

It's fantastic and it's opening different doors, if it does come through that the children can be selected to present their work [to their parents and the wider community] that would be fantastic. They would absolutely love it and some children would thrive on that, they would be in their element doing that. (Gail)

This project has made me realise how research can be used in a way to empower pupils, teachers and the school where each school has different projects to suit their needs and the school develops a very impressive and bespoke pupil-centred project. (Eva)

\section{Obstacles}

For some teachers, a lack of time, as noted in the research cited in the literature review, restricted the potential of the PARPP involvement in the school. As several participants noted: 
I would like the other teachers to show a bit of keenness and interest but I know they're all busy... What I wanted was for the children to generate information but what I got was, 'oh there's not enough time', 'oh you can't take the kids out of other lessons' (Eva)

It's [doing child-led research] is all tied up with the resources of time and whether we would be able to do it any differently'. (Helen)

Gail explained how a 'busy half term with lots of school visits 'would inevitably limit the involvement of the pupils in their PARPP project:

If we had more time we could involve them more. That would be ideal, but I'm just thinking about the time involved, there's no time after this afternoon and I don't think it would happen just with this half term cos there's lots of visits and trips. (Gail)

In some schools (not included in this paper) the PARPP project was consistently perceived as additional work which was separate to pupils' curriculum-led learning which mean that it dropped down the school priorities, even where individual teachers had initially championed it. Sometimes, where projects got off the ground initially, they were left to develop in isolation, for example, as a separate Schools Council initiative. This meant that some projects did not fully develop. Even in some very successful projects, working with pupils to enhance their voice was sometimes seen as difficult to locate within established teaching and learning activities as evidenced in this exchange:

I: Did PARPP enhance the pupil voice in school?

$N$ : I suppose it has done, yes. It certainly, it does to a limited extent, it does over the period which you are discussing it, and we make reference to it from time to time but it would be better if we could keep the momentum going but I haven't managed to do that.

\section{I: What do you think's made it difficult?}

$N$ : I just haven't made the time to do it and I should have done but I just don't know how to manage that really... It's extending the curriculum, it's providing a bigger classroom for us but the children might not see that as a learning environment in the way that we want them to... (Nicola)

This extract highlights the difficulty for teachers of managing and developing a project once it has been implemented so it can be sustained. For this to take place, projects that focus on understanding and developing the pupils' voice often need to be prioritised within the school more effectively than was often possible. However, despite these obstacles, teachers in all of the PARPP projects discussed in this paper, felt that some progress had been made and that the project overall was contributing to an enhanced learning environment for pupils and teaching staff.

It will be interesting to see what the children's views are. I think we need to follow the year two up to find out whether it's actually eased their transition, whether it's set their minds at rest and then we will definitely know whether it was worth doing or not 


\section{Conclusions}

As previously stated, this paper has sought specifically to ask can observing and/or experiencing pupil-led research help teachers more readily appreciate and support pupils as researchers in their own right. The interviews suggested that all the teachers did show an increased awareness of how pupils, through child-led, participatory research activities, could be more actively involved in decisions that affect their lives in school (and beyond). Even though in the initial meetings with teachers to discuss the project teachers had expressed a lack of knowledge and confidence about participation research methods (researcher fieldnotes). This initial lack of knowledge confirmed the extent to which exposure to participatory research methods is traditionally absent from current initial teacher-training research programmes. However, it contradicts the recommendations of the BERA/RSA Report, Research and the Teaching Profession (2016) which identifies four ways in which research could and should contribute to initial teacher education and ongoing researcher development, of which the following is the most relevant to the work undertaken by PARPP:

[...] the content of teacher education programmes may be informed by research-based knowledge and scholarship, emanating from a range of academic disciplines and epistemological traditions (p.5|).

Even though pupil-led research remains more problematic than other, more mainstream teacher or enquiry-led methods for teachers, its importance, in terms of repositioning pupils as active agents in their own learning environment, should not, as this paper has hopefully indicated, be underestimated. However, encouraging teachers to engage in pupil-led research requires a reconceptualisation of the traditionally hierarchical relationship between teachers and their pupils and the perceived utility of research in teacher-education and teaching practices which all tend towards a teacher-dominated view of the school environment and pupil identities, roles and experiences within it. In comparison, Driessnack (2006) writes how co-researching with children has:

[..]the potential to shift the focus from adult-determined interests and agendas and redirect them, generating new hypotheses that might be more child-determined... (p.1432)

This then is the ultimate value of pupil-led research in schools for teachers; it offers up the chance for teachers to gin an insight into more, or different, kinds of understanding about how pupils are experiencing their lives at school than would be possible if they, the adults, were organising research design and processes. Relinquishing that power and offering it to pupils, helping them to see school as a research environment and learning as a form of 
enquiry allows both teachers and pupils to rethink, extend and enrich their relationship in that environment as both researchers and the researched.

\section{References}

BERA / RSA report on Research and the Teaching Profession (BERA, 2014) Available at: https://www.bera.ac.uk/wp-content/uploads/2013/12/BERA-RSA-Research-TeachingProfession-FULL-REPORT-for-web.pdf.).

Beycioglu, K., Ozer, N. and Uguralu, C. (2011) Teachers' views on educational research, Teaching and Teacher Education, Vol, 26, No(4) pp. 1088-1093.

Bucknall, S. (2012) Children as Researchers in Primary Schools: Choice, Voice and Participation, Oxford: Routledge.

Clark, A. and Statham, J. (2005) 'Listening to young children: experts in their own lives', Adoption and Fostering, vol. 29, no.1, pp. 45-56.

Clark, A. (2003) 'The Mosaic approach and research with young children', in V. Lewis, M. Kellet,C. Robinson, S. Fruser and S. Ding (eds) The reality of research with children and young people, London: Sage Publications, pp. 157-61.

Clark, A. and Moss, P. (2001) Listening to young children: The Mosaic approach, London: National Children's Bureau for the Joseph Rowntree Foundation.

Cremin, H. \& Slatter, B. (2004) Is it possible to access the 'voice' of pre-school Children? Results of a research project in a pre-school setting, Educational Studies Vol. 30 , No. 4, pp. 457-470.

Cohen, M. Manion, L. \& Morrison, K. (eds) (2007) Research Methods in Education. Routledge: Oxon

Dockett, S. Einarsdottir, and Perry (2009) Researching with children: ethical tensions, Journal of Early Childhood Research Vol. 7, No. 3, pp. 283-298.

Department for Education (2014) Listening to and involving children and young people: Statutory guidance about listening to the 'pupil voice' and involving pupils in decision making.

Driessnack, M. (2006) Draw-and-tell conversations with children about fear. Qualitative Health Research, 16 (10), 1414-1435.

Early Childhood Action (2017) Early Childhood Action http://www.earlychildhoodaction.com/contact.html. Accessed October 31, 2017.

Einarsdottir, J., Dockett, S., \& Perry, R. (2009) Making meaning: children's perspectives expressed through drawings, Early Child Development and Care, Vol. 179, No. (2) pp. 217 232. 
French, A. and Hobbs, D. (2017) "'So how well did it really go"? Working with primary school pupils as project evaluators: a case study', TEAN Journal, 9(1), pp. 56-65

Gallacher, L.A \& Gallagher, M. (2008) Methodological immaturity in childhood research?: Thinking through 'participatory methods" Childhood, vol 15, no. 4, pp. 499-516.

Greene, S. M and Hill, M. (2005) Researching children's experiences: methods and methodological issues. in S. Greene \& D. Hogan (eds), Researching children's experiences: approaches and methods. pp. 1-21.

Greig, A., Taylor, J. and MacKay, T. (2007). Doing Research With Children (2nd Ed.). London: Sage.

Heath, S., Charles, V., Crow, G. and Wiles, R. (2007) Informed consent, gatekeepers and gobetweens: negotiating consent in child- and youth-orientated institutions, British Educational Research Journal Vol. 33 , No. 3 pp.283-299.

House, R. (ed) (2011) Too Much, Too Soon? - Early Learning and the Erosion of Childhood, Hawthorn Press, Stroud.

Hunt, R. (ed) (2011) Too Much, Too Soon? Early learning and the erosion of childhood, London: Hawthorne.

Jones, K. (2011) Central, local and individual continuing professional development (CPD) priorities: changing policies of CPD in Wales Professional Development in Education Vol 37 No 5 November 2011, pp. 759-776

Jones, K. and O'Brien, J. (Eds) (2014) European Perspectives on Professional Development in Teacher Education London: Routledge.

Jones, L., Osgood, J., Holmes, R., and MacLure, M. (2014). (Re)assembling, (Re)casting, and (Re)aligning Lines of De- and Re-territorialisation of Early Childhood. International Review of Qualitative Research. 7(1), pp.58-79.

Kellett, M., (2010) Rethinking Children and Research, Continuum | Published: London.

Kerawalla, L. (2014) Young researchers' use of the 'Our Story' app to create multimedia experiential research narratives: putting 'me' back into accounts of research process.

Presented at ICERI, Seville, Spain, Nov 2014.

Kerawalla, L. \& Webb, R. (2014) 'I did it mostly by myself': MyShout! and how it was used by a 12-year-old researcher to support his own social research project. In Proceedings of EduLearn14, Barcelona, Spain, 7-9 July, 2014.

Krappmann, L. (2010) The weight of the child's view (Article 12 of the Convention on the Rights of the Child)The International Journal of Children's Rights, Volume 18, Issue 4, pp. $501-513$. 
Leat, D., Reid, A. and Lofthouse, R. (2015) Teachers' experiences of engagement with and in educational research: what can be learned from teachers' views? Oxford Review of Education, Published on line March 2015.

Lewis J., and McNaughton-Nicholls, C. (2014) 'Design Issues' in Ritchie, J., Lewis J., McNaughton-Nicholls, C., and Ormston R. (eds) Qualitative Research Practice 2nd edition, London: Sage Publications. pp47 - 76

Lowe R.J. (2012) Children Deconstructing Childhood, Children \& Society Vol 26, No (4) pp. 269-279.

Newman, L. \& Mowbray, S. (2012), We were expected to be equal": Teachers and academics sharing professional learning through practitioner inquiry. Teachers and Teaching: Theory and Practice. Vol 18, No 4. pp.455-468.

Oldenburg, R. (2000) Celebrating the Third Place: Inspiring Stories about the "great Good Places" at the Heart of Our Communities, New York: Marlowe \& Company.

Osgood, J. (2016) Post-modern perspectives of childhood in S. Powell, S \& K. Smith (eds) An Introduction to Early Childhood Studies, 4th Edition. London: Sage.

Punch, S. (2002) Interviewing Strategies with Young People: the 'Secret Box', Stimulus Material and Task-based Activities. Children and Society Vol. 16 pp. 45-5.

Rinaldi, C. (2006) Creativity as a quality of thought', in C Rinaldi (ed.), In dialogue with Reggio Emilia: Listening, researching, and learning, Routledge, Oxon UK, pp. 111-120.

Ruck, M. D., and Horn, S. S. (2008). Charting the landscape of children's rights. Journal of Social Issues, Vol, 64, No 4, pp. 685-700.

Yin, R. K. (2003) Case Study Research: Design and Methods, London: Sage Publications. 